\title{
Specific transgenerational imprinting effects of the endocrine disruptor methoxychlor on male gametes
}

\author{
Christelle Stouder $^{1}$ and Ariane Paoloni-Giacobino ${ }^{1,2}$ \\ ${ }^{1}$ Department of Genetic and Laboratory Medicine, Geneva University Hospital, 1211 Geneva 14, Switzerland and \\ ${ }^{2}$ Swiss Center for Applied Human Toxicology, University of Geneva Medical School, 1211 Geneva 4, Switzerland \\ Correspondence should be addressed to A Paoloni-Giacobino at Department of Genetic and Laboratory Medicine, CMU, \\ 1 Michel-Servet, 1211 Geneva 4, Switzerland; Email: ariane.giacobino@unige.ch
}

\begin{abstract}
Endocrine-disrupting chemicals (EDCs), among which methoxychlor (MXC), have been reported to affect the male reproductive system. This study evaluates the possible deleterious effects of MXC on imprinted genes. After administration of the chemical in adult male mice or in pregnant mice we analyzed by pyrosequencing possible methylation defects in two paternally imprinted (H19 and Meg3 (Gt/2)) and three maternally imprinted (Mest (Peg1), Snrpn, and Peg3) genes in the sperm and in the tail, liver, and skeletal muscle DNAs of the adult male mice and of the male offspring. MXC treatment of adult mice decreased the percentages of methylated CpGs of Meg3 and increased those of Mest, Snrpn, and Peg3 in the sperm DNA. MXC treatment of pregnant mice decreased the mean sperm concentrations by $30 \%$ and altered the methylation pattern of all the imprinted genes tested in the F1 offspring. In the latter case, MXC effects were transgenerational but disappeared gradually from F1 to F3. MXC did not affect imprinting in the somatic cells, suggesting that it exerts its damaging effects via the process of reprogramming that is unique to gamete development. A systematic analysis at the $\mathrm{CpG}$ level showed a heterogeneity in the CpG sensitivity to MXC. This observation suggests that not only DNA methylation but also other epigenetic modifications can explain the transgenerational effects of MXC. The reported effects of EDCs on human male spermatogenesis might be mediated by complex imprinting alterations analogous to those described in this study.

Reproduction (2011) 141 207-216
\end{abstract}

\section{Introduction}

Endocrine-disrupting chemicals (EDCs) are synthetic or natural compounds that may affect the function of the endocrine system. Methoxychlor (MXC), an EDC used as a pesticide, is a synthetic organochlorine derived from 1,1,1-trichloro-2,2-bis(4-methoxyphenyl)ethane (DDT), possessing estrogenic, anti-estrogenic, and antiandrogenic activities (Cummings 1997, Gaido et al. 2000, Alworth et al. 2002).

MXC administration in adult male rats has been found to induce abnormalities in male reproductive tract, affecting testes, prostate, and seminal vesicle development as well as spermatogenesis (Okazaki et al. 2001).

MXC administration in early pregnancy or during the perinatal and neonatal periods has been found to result in adult-onset abnormalities in both female and male animals. In female rodents, MXC induced reductions in the pregnancy outcome (Swartz \& Eroschenko 1998), in ovarian functions, and in ovulatory rates (Eroschenko et al. 1995, 1997) that could be attributed to a possible dysfunction of the hypothalamic-pituitary-ovarian axis. MXC was also found to induce a decrease in the ovarian estrogen receptor $\beta$ (ESR2) expression (Armenti et al. 2008). In male rodents, MXC induced a decrease in sexual arousal (Eroschenko et al. 2002), an increase in sexual maturation (Amstislavsky et al. 2004), a decrease in the circulating testosterone level (Amstislavsky et al. 2006), and decreases in testis weight, Sertoli cell number, and spermatogenesis potential (Staub et al. 2002).

MXC release into the environment is therefore considered potentially hazardous to human development and/or reproduction and its use is currently restricted within the United States. In the past century, a decline in sperm counts has been documented in young healthy men of industrialized countries, which could be responsible for the currently observed decline in fertility rates (Roeleveld \& Bretveld 2008). Studies performed in humans reported that exposure to pesticides may decrease spermatogenesis and male fertility (Roeleveld \& Bretveld 2008). Furthermore, a significant association was found between organochlorine concentrations in the semen of male volunteers and sperm quality (Pant et al. 2007).

It is therefore important to know more about the genetic mechanism of the deleterious effects of MXC. In particular, the latter might act by altering the epigenetic programming of the genome, i.e. by modulating gene 
expression without modifying the underlying DNA sequence. The perinatal exposure to MXC has, indeed, been shown to cause an hypermethylation of the ESR2 promoter and of ten other genes in the ovary (Zama \& Uzumcu 2009).

A functionally important player in epigenetic gene regulation is imprinting. In an imprinted gene, the expression of the two alleles depends on their parental origin. It occurs at specific sites within or surrounding the gene, called differentially methylated domains (DMDs). Within a DMD, one parental allele is methylated on all or the majority of its CpG dinucleotides, and the opposite parental allele is methylated on none or a small percentage of its $\mathrm{CpG}$ dinucleotides. One of the well-characterized consequences of DNA methylation is silencing of the corresponding allele ( $\mathrm{Li}$ et al. 1993, Kaneda et al. 2004). An epigenetic reprogramming initiated by the erasure of preexisting DNA methylation marks takes place during the embryonic development in primordial germ cells. Imprint reestablishment follows in both female and male germ lines during gametogenesis that occurs both during embryonic development and in the gonads after puberty (Lee et al. 2002). Reprogramming differs from one imprinted gene to the other in terms of timing and extent of methylation. For instance, in the mouse paternally methylated H19, Meg3, and Rasgfr1 genes, DMD methylation is erased although not totally in Meg3, and H19 at e12.5 and DMD remethylation occurs at various rates between e12.5 and the mature sperm age (Li et al. 2004).

The effects of EDCs on imprinting have already been studied. Vinclozolin (VCZ), a fungicide possessing an anti-androgenic activity affected spermatogenesis inducing decreases in sperm number and motility and an increase in apoptosis in the seminiferous tubules germ cells (Shimamura et al. 2002, Anway et al. 2005, 2006, 2008, Buckley et al. 2006, Elzeinova et al. 2008). MXC, administered perinatally or during gestation, was also found to affect spermatogenesis in the adult or in the offspring respectively (Chapin et al. 1997, Anway et al. 2005). An intriguing observation of these studies is that the effects on male genital tract and spermatogenesis were found to be transgenerational, extending from $\mathrm{F} 1$ to F4 for VCZ (Anway et al. 2005, 2006, 2008) and from F1 to F2 for MXC (Anway et al. 2005). The effects of VCZ on reproduction were reported to be correlated with alterations in the germ line DNA methylation pattern (Anway et al. 2005). VCZ, administered to pregnant mice, during a period of time encompassing embryo sex differentiation, affected both spermatogenesis and the sperm methylation pattern of paternally and maternally imprinted genes in the offspring. The effects of VCZ on the imprinted genes were transgenerational but disappeared gradually from F1 to F3 (Stouder \& Paoloni-Giacobino 2010). However, a systematic study of the effects of MXC on imprinted genes has never been performed.
A few mouse and human DMDs have been well characterized. They are, in particular, the DMDs of the maternally expressed paternally methylated H19 (Tremblay et al. 1997) and Meg3 (Li et al. 2004) genes and of the paternally expressed maternally methylated small nuclear ribonucleoprotein polypeptide N (Snrpn; Shemer et al. 1997), Mest (Kaneko-lshino et al. 1995), Peg3 (Kuroiwa et al. 1996), and the potassium channel 1 (Kcnq1; Smilinich et al. 1999) genes.

The aim of this study is to evaluate systematically the possible deleterious effects of MXC on imprinted genes. MXC was administered in adult male mice or in pregnant mice at the time of embryo sex differentiation. We investigated possible methylation defects in the DMDs of two paternally imprinted (H19 and Meg3) and three maternally imprinted (Mest, Snrpn, and Peg3) genes in the sperm as well as in the tail, liver, and skeletal muscle DNAs of the adult mice and male offspring over three generations.

\section{Results}

MXC or vehicle only was administered to 8 -week-old male mice during 8 consecutive days and a sperm count was performed. As shown in Fig. 1, MXC did not alter the mouse sperm count. The methylation status of the paternally methylated $\mathrm{H} 19$ and Meg3 genes and maternally methylated Mest, Snrpn, and Peg3 genes was studied in the same animals by DNA bisulfite treatment. For each imprinted gene, a number of CpGs varying between 5 and 23 were analyzed. The DNA bisulfite treatment technique enables to measure the amount of methylated as compared to total (methylated and nonmethylated) CpGs. In the sperm of control mice, the number of methylated CpGs was close to the theoretical imprinted gene values of 100 and $0 \%$ of the total CpGs in paternally or maternally methylated genes respectively. MXC treatment induced significant changes in the methylation pattern of our five target genes in sperm, with the exception of H19. The number of methylated CpGs of Meg3 was decreased to a value of 96\% and those of Mest, Snrpn, and Peg3 were increased

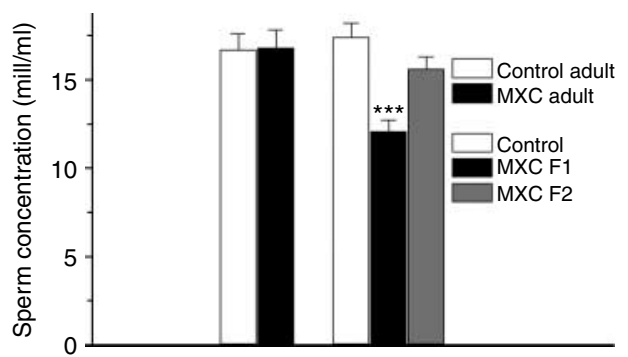

Figure 1 Motile sperm concentration, in millions of spermatozoa/ml of sperm, of vehicle only (control adult) or methoxychlor (MXC)administered male mice (MXC adult) or of vehicle only (control) or MXC-administered females' F1 and F2 offspring (MXC F1 or F2). The results are the means \pm S.E.M. of six to nine mice. ${ }^{* * *} P<0.005$. 


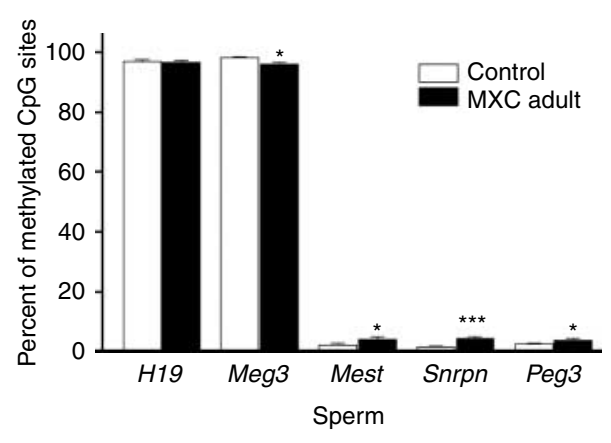

Figure 2 Methylation status of the paternally methylated H19 and Meg3 genes and of the maternally methylated Mest, Snrpn, and Peg3 genes in the motile sperm fraction of vehicle only (control) or MXCadministered male mice (MXC adult). The results are the means \pm S.E.M. of six to seven mice. They represent the number of methylated CpG sites and are expressed in percent of methylated CpG sites. $* * * P<0.001 ; * P<0.05$ versus controls.

(respective values of $4.1,4.4$, and $3.6 \%$; Fig. 2). The methylation patterns of our five target genes were also analyzed in the liver and skeletal muscle. The amount of methylated CpGs in the control mice was close to the theoretical imprinted gene value of $50 \%$ of the total CpGs (DNA methylation/unmethylation present in one of the two parental alleles only) in all the imprinted genes tested and no difference could be detected between control and MXC-treated mice (Fig. 3A and B).

MXC or vehicle only was also administered to pregnant female mice during a gestational period encompassing the erasure of methylation marks and the beginning of the methylation resetting within imprinted genes and a sperm count was performed in controls and in F1 and F2 offspring of pregnant MXC-administered female mice. As shown in Fig. 1, the mean sperm concentrations of the MXC females' offspring were only $70 \%$ in the $\mathrm{F} 1(P<0.001)$ and restored to $90 \%$ in the $\mathrm{F} 2$ of that of the controls. The methylation status of H19, Meg3, Mest, Snrpn, and Peg3 genes was studied in controls and in MXC females' F1, F2, and F3 offspring. In the sperm of control mice, the percentage of methylated $\mathrm{CpG}$ sere close to the theoretical imprinted gene values of 100 and $0 \%$ of the total CpGs in paternally or maternally methylated genes respectively. MXC treatment induced significant changes in the sperm of male offspring (F1). The number of methylated CpGs of H19 and Meg3 was decreased (respective values 91.4 and $89.5 \%$ ) and those of Mest, Snrpn, and Peg3 increased (respective values 10.2, 11.3, and 7.5\%) (Fig. 4). The MXC effects were all highly significant $(P<0.001)$. As demonstrated by the S.E.M., the interindividual variations were relatively small. The effects of MXC were still present and highly significant $(P<0.01$ and $P<0.001)$ in the H19, Meg3, Mest, and Snrpn genes of F2 offspring sperm. However, a trend toward a recovery between F1 and F2 sperm was observed, the methylated $\mathrm{CpG}$ values being significantly higher in the F2 than in the F1 offspring for Meg3 $(P<0.005)$ and lower in the F2 than in the F1 offspring for Mest, Snrpn, and Peg3 $(P<0.001, P<0.005$, and $P<0.005$ respectively). Only $\mathrm{H} 19$ was as much affected in the $\mathrm{F} 2$ as in the F1 offspring. In the F3 offspring, the effects of MXC could not be detected anymore in our five target genes (Fig. 4).

In the tail, liver, and skeletal muscle of control offspring the amount of methylated CpGs was close to the theoretical value of $50 \%$ of the total CpGs in all the imprinted genes tested and no decrease in this value could be detected in MXC-administered female F1-F3 offspring as compared to controls (Fig. 5A-C). Some variations in the amount of methylated $\mathrm{CpGs}$ between the groups can be seen in Fig. 5B and C. It consists of significantly higher numbers of methylated $\mathrm{CpGs}$ in liver Meg3 F2, in muscle Mest F1, and in both tissue Snrpn F2 and F3. It is noteworthy that the amount of methylated CpGs in the Snrpn gene of somatic cells was systematically slightly lower than the theoretical value of $50 \%$ in most of the groups tested (Figs $3 \mathrm{~A}$ and $\mathrm{B}$ and $5 \mathrm{~A}-\mathrm{C}$ ). This incomplete imprinting status was to some extent corrected in some groups of mice.

In conclusion, MXC administration both in adult mice and during gestation altered the methylation patterns of imprinted genes in the male germline cells but not in the somatic cells.

The effects of MXC administration on the methylation status of each of the individual CpGs tested in our five imprinted genes are shown in Table 1.
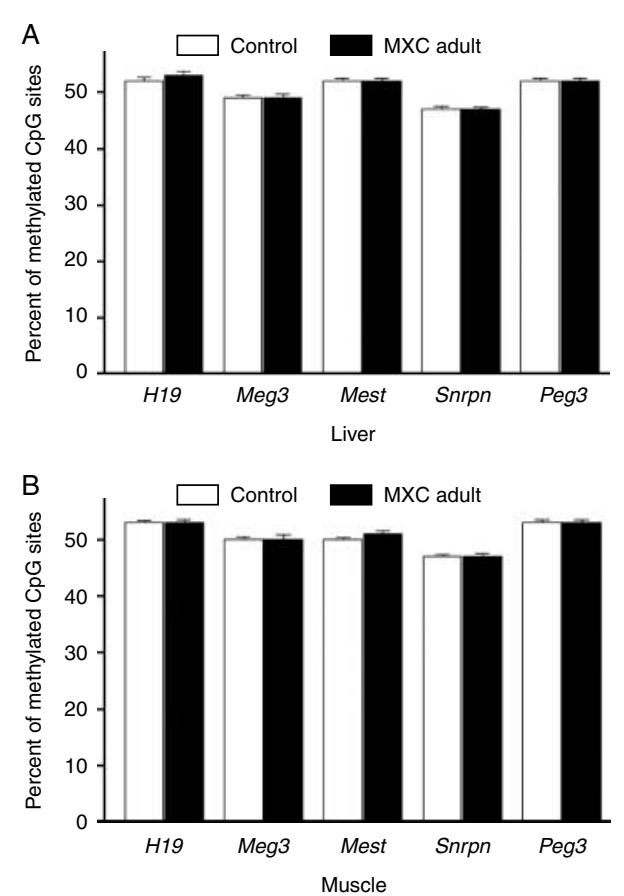

Figure 3 Methylation status of the paternally methylated H19 and Meg3 genes and of the maternally methylated Mest, Snrpn, and Peg3 genes (A) in the liver and (B) skeletal muscle of vehicle only (control) or MXCadministered male mice (MXC adult). The results are the means \pm S.E.M. of six mice. They represent the number of methylated CpG sites and are expressed in percent methylated of CpG sites. 


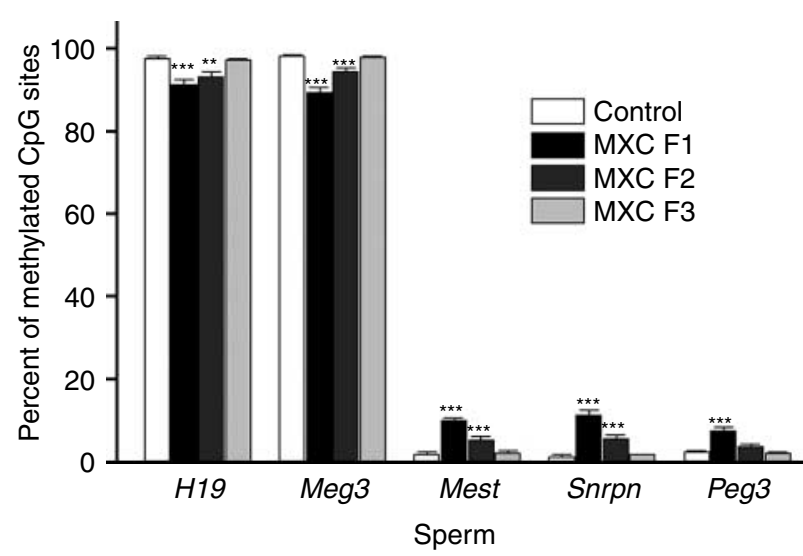

Figure 4 Methylation status of the paternally methylated $\mathrm{H} 19$ and Meg3 genes and of the maternally methylated Mest, Snrpn, and Peg3 genes in the motile sperm fraction of vehicle only (control) or of MXCadministered females' F1-F3 offspring (MXC F1-F3). The results are the means \pm s.E.M. of nine to ten mice. They represent the number of methylated $\mathrm{CpG}$ sites and are expressed in percent of methylated CpG sites. ${ }^{* * *} P<0.001 ;{ }^{* *} P<0.01$ versus controls.

MXC administered to adult male mice significantly affected, in the sperm, the methylation pattern of all the CpGs in the maternally methylated genes Mest and Snrpn. However, it did not affect 2 out of 6 CpGs of the maternally methylated gene Peg3 and 3 out of 6 and 5 out of $15 \mathrm{CpGs}$ in the paternally methylated genes H19 and Meg3 respectively.

MXC administered to pregnant female mice significantly affected, in the sperm of the F1 offspring, the methylation pattern of all the CpGs in the maternally methylated genes, Mest, Snrpn, and Peg3. It did not affect, however, 1 out of 6 and 4 out of 15 CpGs in the paternally methylated genes $\mathrm{H} 19$ and Meg3 respectively.

If the methylation patterns of the CpGs in F1 and F2 are compared, it can be seen, as expected, that when a significant effect of MXC is seen in F2, it always preexists in F1. It can also be seen, as expected, that the significance of MXC effects are either similar in F1 and F2 or more marked in the former. These expected observations confirm the reliability of the CpG methylation analysis. In the maternally methylated genes of the F2 offspring, MXC affected significantly the methylation pattern of all the CpGs of Mestbut in Snrpn and Peg3 one out of four and four out of six CpGs were rescued respectively. In the paternally methylated genes $\mathrm{H} 19$ and Meg3, 2 out of 6 and 11 out of $15 \mathrm{CpGs}$ were rescued respectively. The possible effects of MXC administration on the methylation status of each of the individual CpGs in our five imprinted genes were not analyzed and were not shown in F3.

\section{Discussion}

This study is the first to address the possible effects of MXC administration on canonical imprinted genes. We investigated the possibility of both direct and transgenerational effects of MXC on maternally imprinted and paternally imprinted genes in mouse sperm and somatic cells.

The pyrosequencing technique was chosen and used throughout this study since it was previously shown to yield results similar to those obtained by the subcloningsequencing technique (Stouder et al. 2009).

In adult mice, MXC administration during the 8 days did not affect the sperm count. MXC administration in adult male rats during the 28 days was found to induce a decrease in the number of sperm cells in the caudal epididymis (Okazaki et al. 2001). In our study, the short time that elapsed between the end of the MXC treatment and the sperm collection would not allow the spermatogonial cells to become sperm. This might explain why no effect of MXC on sperm counts was observed. Moreover, the discrepancy between our results and those of Okazaki et al. (2001) might be explained by the higher doses of MXC used in the latter study. Our results, however, show for the first time the direct effects of MXC on the methylation pattern of four out of the five paternally imprinted and maternally imprinted genes tested in the sperm. It is noteworthy that MXC affected specifically the imprinted genes of the germline leaving those of the somatic cells (liver and skeletal muscle) untouched.

In pregnant mice, MXC administration during a gestational period encompassing the erasure of methylation marks and the beginning of the methylation resetting within imprinted genes decreased the sperm concentration and altered the methylation patterns of the two paternally imprinted (H19 and Meg3) and three maternally imprinted (Mest, Snrpn, and Peg3) genes in the sperm of F1 offspring. Again, MXC affected specifically the imprinted genes of the germline leaving those of the somatic cells (tail, liver, and skeletal muscle) untouched. The effects of MXC on spermatogenesis were found to be transgenerational, extending from F1 to F2 (Anway et al. 2005). They were transferred through the male germ line to males of the subsequent generation. The effects of VCZ on reproduction were reported to be correlated with alterations in the germ line DNA methylation pattern (Anway et al. 2005). VCZ administered to pregnant mice decreased the sperm concentration and affected the methylation status of imprinted genes in the sperm of F1-F3 offspring (Stouder \& Paoloni-Giacobino 2010). It was also found to alter the methylation pattern of Peg3 in somatic cells of F2 and F3 offspring (Stouder \& Paoloni-Giacobino 2010). Altogether, these data and those of this study show a consistent deleterious effect of EDCs on male gametogenesis and imprinting in the sperm and inconsistent effects of EDCs on somatic cells. By analogy, we can postulate that the reported effects of EDCs on human male spermatogenesis and fertility rates (Roeleveld \& Bretveld 2008) might involve imprinting alterations in the sperm. 
Since MXC affects only the sperm cells, we can consider that it exerts its damaging effects via the process of reprogramming that is unique to gamete development.
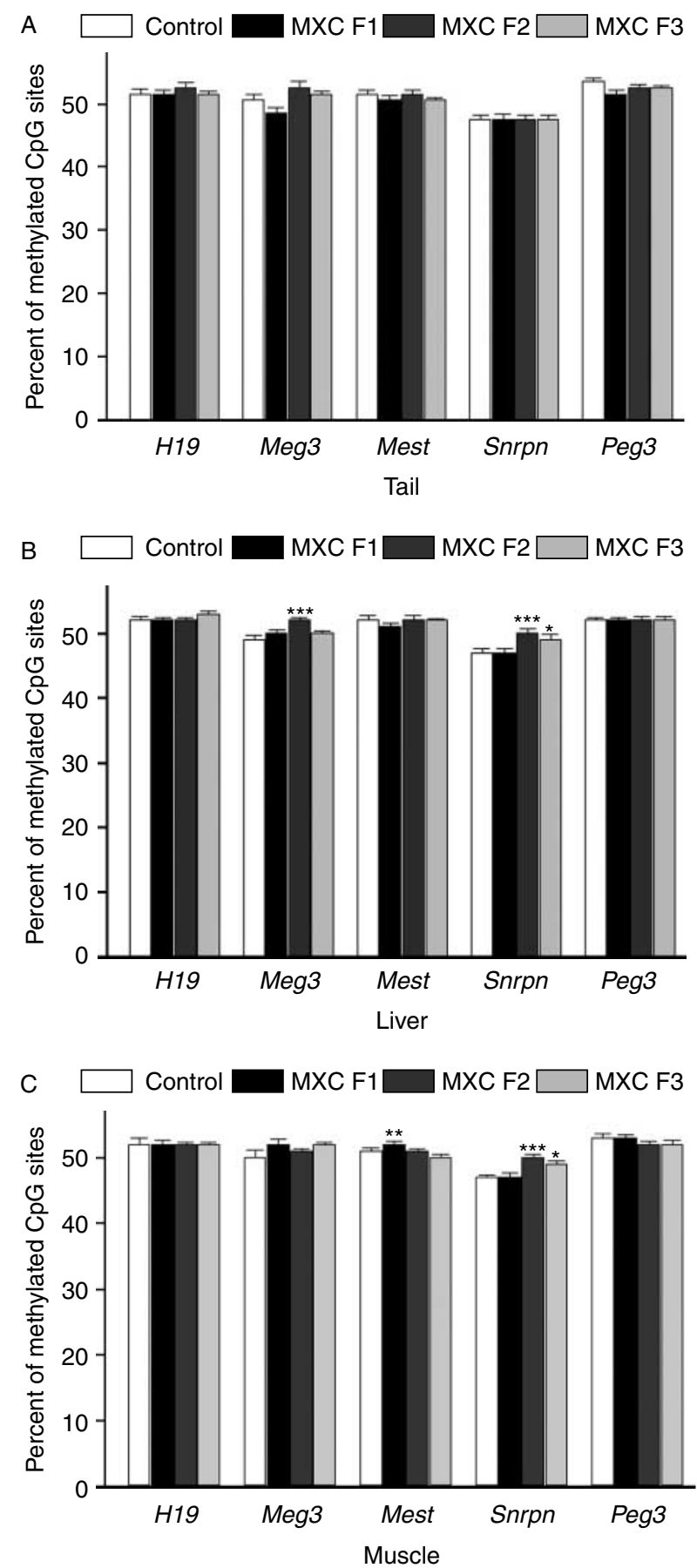

Figure 5 Methylation status of the paternally methylated $\mathrm{H} 19$ and Meg3 genes and of the maternally methylated Mest, Snrpn, and Peg3 genes (A) in the tail, (B) liver, and (C) skeletal muscle of vehicle only (control) or of MXC-administered females' offspring (MXC F1-F3). The results are the means \pm S.E.M. of nine to ten mice. They represent the number of methylated $\mathrm{CpG}$ sites and are expressed in percent of methylated CpG sites. ${ }^{* * *} P<0.005 ;{ }^{* *} P<0.01 ;{ }^{*} P<0.05$ versus controls.
It is generally admitted that, due to the mechanisms of erasure and reprogramming, abnormal epigenetic states are not transmitted to the next generation. However, it has been shown previously that VCZ administration or superovulation in pregnant female mice induces epigenetic mark defects that can survive transgenerational reprogramming (Anway et al. 2005, Stouder et al. 2009, Stouder \& Paoloni-Giacobino 2010). It has been shown in this study that the imprinting defects induced by MXC are also transgenerational. The resistance to reprogramming in MXC-exposed fetus is partly reversed in the reprogramming period of the first subsequent gestation (F2) and does not resist the reprogramming period of the second subsequent gestation (F3). The reason for the partial and temporary failure of the reprogramming system is far from being elucidated.

The systematic analysis performed in this study at the CpG level in our target imprinted genes should allow a better understanding of the mechanism of the deleterious effects of MXC. We will discuss, first, the sensitivity to MXC and, second, the resistance to reprogramming of the individual CpGs. An important finding of this study is a heterogeneity of the CpG sensitivity to MXC or resistance to reprogramming. Differences in the response of the various CpGs of a DMD to exogeneous factors have never been described, except in an unpublished study of our group showing that only three out of six CpGs of H19 gene were affected by alcohol exposure (C Stouder, E Somm \& A Paolini-Giacobino, unpublished observations).

First, in F1 offspring sperm, though all CpGs were affected by MXC in the maternally methylated DMDs, a few CpGs resisted MXC in the paternally methylated DMDs. This observation suggests that the methylation process in the paternally methylated DMDs is less sensitive to MXC than the inhibition of remethylation in the maternally methylated genes. A few CpGs, CpG 5 of $\mathrm{H} 19$ and CpGs 6 and 8 of Meg3, were not affected by MXC in both adult and embryo. In most of the cases, however, the CpGs resisting MXC in the adult or embryo were different. The CpG specificity of the MXC effects suggests that the DNA methyltransferases (DNMTs; Jia et al. 2007) might be involved. If this is the case, the DNMTs involved in the adult and/or embryo DNA methylation should be different.

Second, in F2 offspring sperm, if the paternally methylated genes are considered, it can be seen that most of the CpGs of the H19 (4 out of 5) and a minority of the CpGs of Meg3 (4 out of 15) resisted reprogramming. If the maternally methylated genes are considered, all the CpGs of Mest, most of the CpGs of Snrpn (three out of four), and a minority of the CpGs of Peg3 (two out of six) resisted reprogramming. Therefore, the dichotomy observed between paternally methylated and maternally methylated genes in the sensitivity to MXC is not observed when the resistance to reprogramming is considered, suggesting a different mechanism for the 


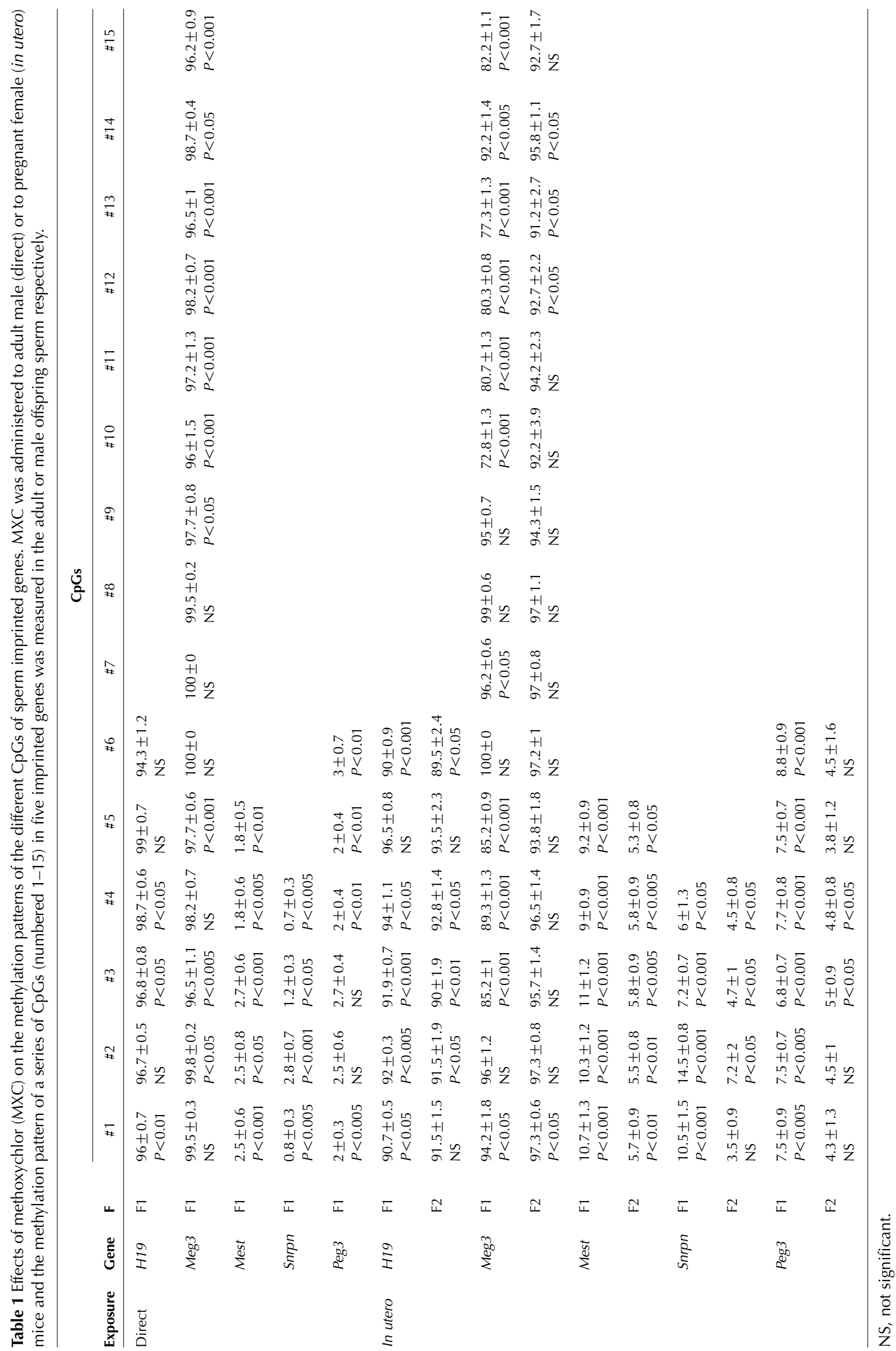


latter. Li et al. (2004) have shown that a relatively high level of methylation was retained in Meg3 and H19 of e12.5 germ cells when the methylation of other imprinted genes was totally removed. It could, therefore, be proposed that a resistance to reprogramming occurs when the erasure step of reprogramming is incomplete. Our results, obtained on a different genetic background, showing that most of the CpGs of the H19 but a minority of the CpGs of Meg3 resisted reprogramming are not in line with this hypothesis. It has been postulated that, in male and female germ cells, epigenetic marks other than DNA methylation, perhaps those based on histone modifications, are not removed during reprogramming, allowing parental alleles to remember their origin (Lucifero et al. 2004, Morgan et al. 2005, Arnaud 2010). If MXC affects histone modifications, it might create an epigenetic mark that, by resisting reprogramming, would explain why its effects for some CpGs are transgenerational and for some or most of the CpGs still observed in F2. The Meg3 DMD of the silent paternal allele has been reported to be hypoacetylated on histones 3 and 4 ( $\mathrm{H} 3$ and $\mathrm{H} 4)$, while the Dlk1 DMD of the active maternal allele was highly acetylated on both histones, indicating that both histone acetylation and DNA methylation are involved in maintaining the imprinting of Meg3-Dlk1 genes (Carr et al. 2007). It would be interesting to study the possible effects of MXC on $\mathrm{H} 3$ and $\mathrm{H} 4$.

The discrepancy observed between the effects of MXC on the methylation status of sperm imprinted genes, which persisted in the F2 offspring, and the effect of MXC on the sperm count, which had already disappeared in the F2 offspring, does not necessarily mean that the decrease in the sperm count observed in the F1 offspring is not related to the changes in the methylation status imprinted genes of the sperm. The same discrepancy has been reported after VCZ administration (Stouder \& Paoloni-Giacobino 2010). It suggests that a certain threshold of imprinting imbalance has to be reached to translate into a detectable decrease in spermatogenesis.

This study shows that MXC administration to pregnant female mice induces alterations in the methylation pattern of five canonical paternally and maternally imprinted genes in the sperm of the offspring, which are transgenerational but disappear in F3. This study does not give clues on the possibility that the observed methylation changes modify the imprinting status, i.e. the selection of one parental allele for expression. It would definitely be of great interest to answer this question. These effects on the methylation pattern of the five imprinted genes tested were paralleled by a decrease in the sperm concentration observed only in F1. We report a heterogeneity of the responses to MXC of the various CpGs tested, suggesting that, in addition to DNA methylation, MXC might affect specific DNMTs or histone marks.

\section{Materials and Methods}

\section{Mice}

Normal FVB/N mice were purchased from Charles River (Arbresle, France). Two-month-old female mice were naturally mated with male mice of the same age. Next morning, females with a copulation plug were separated into two groups. The dose of a developmental exposure to MXC, with which no adverse effect was observed, has been shown to vary between $20 \mathrm{mg} / \mathrm{kg}$ per day (Okazaki et al. 2001) and $<20 \mu \mathrm{g} / \mathrm{kg}$ per day (Armenti et al. 2008) in rats. It has been reported to be about $40 \mathrm{mg} / \mathrm{kg}$ per day in mice (Swartz \& Eroschenko 1998). In this study, we wanted to investigate the possible effects of MXC on imprinted genes, if possible, in the absence of effects on the sexual development of the offspring. Considering the above literature, we chose a relatively low dose of $10 \mathrm{mg} / \mathrm{kg}$ per day. MXC (Sigma-Aldrich) was suspended in sesame oil and administered intraperitoneally, in doses of $10 \mathrm{mg} / \mathrm{kg}$ per day, to a first group $(n=6-7)$ of 8 -week-old adult male mice during 8 consecutive days. The corresponding control group $(n=6-7)$ consisted of 8-week-old adult male mice injected for the same period with the sesame oil only. The mice were killed by cervical dislocation the day after the last injection. In a second group $(n=9-10)$ pregnant mice received MXC in doses of $10 \mathrm{mg} / \mathrm{kg}$ per day from days 10 to 18 of pregnancy, i.e. during a period encompassing the erasure of imprinted gene methylation marks (when primordial germ cells enter the gonads) and the beginning of the imprinted gene methylation resetting in prospermatogonia (Trasler 2009). The control mothers ( $n=9-10)$ were injected with sesame oil only, from days 10 to 18 of pregnancy and their F1 offspring were used at the age of 2 months as controls. To study the possible transgenerational effects of MXC treatment, F1 and F2 outcross were performed in this group. For F1 outcross, 9-10 F1 males were crossed with 9-10 FVB/N females in order to obtain F2 male offspring and for F2 outcross 9-10 F2 males were crossed with 9-10 FVB/N females to obtain F3 male offspring. F1-F3 offspring were used at the age of 2 months. Only one offspring from each mother was analyzed. Animal protocols used in these studies were approved by the Commission d'Ethique de l'Expérimentation Animale of the University of Geneva Medical School and by the Geneva Veterinarian Office.

\section{Sperm collection}

The mouse vas deferens and epididymis were dissected out, placed into a Petri dish, scored with a razor blade in a droplet of PBS to allow sperm to diffuse into the medium. The latter was then transferred to a microcentrifuge tube and the fragments were allowed to sediment during $30 \mathrm{~min}$ at $37^{\circ} \mathrm{C}$. The supernatant was carefully transferred to another tube, and this procedure was repeated three times. The final supernatant, containing the motile sperm fraction, was carefully removed and centrifuged at $2800 \mathrm{~g}$ for $3 \mathrm{~min}$ to pellet the sperm.

\section{Sperm count}

In some experiments, an aliquot of the supernatant's motile sperm fraction was used for sperm counting, using 

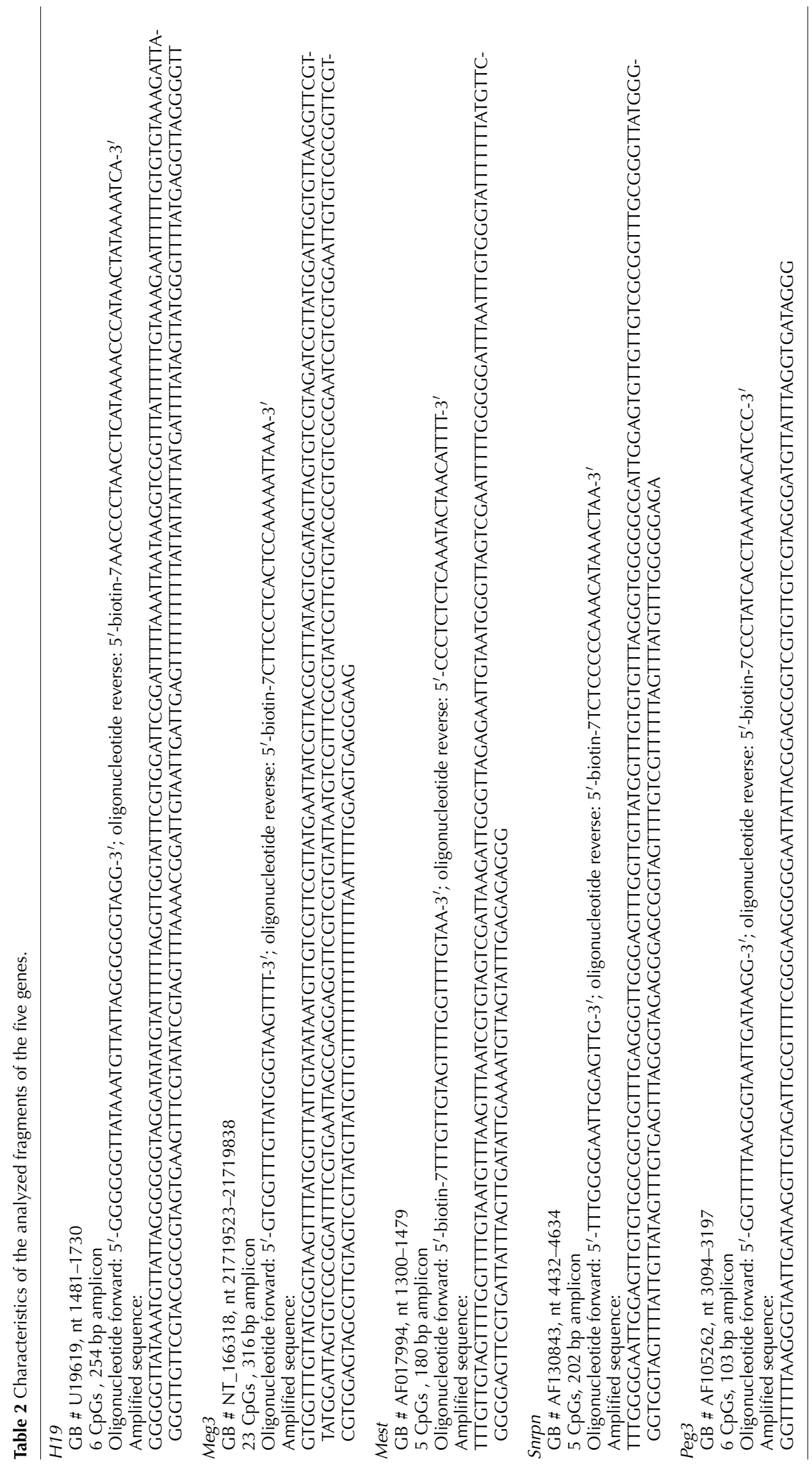
a hemocytometer. The corresponding sperm concentration was calculated using the following formula: cells $/ \mathrm{ml}=$ the average count per square $\times$ dilution factor $\times 10^{4}$ (counts 10 squares).

\section{Tissue collection}

Fragments of $5 \times 5 \mathrm{~mm}$ size of tail, liver, and tibialis anterior muscle were collected, cut into small pieces in a Petri dish, and transferred to DNA-extraction buffer.

\section{DNA isolation}

Motile sperm fraction DNA was extracted using the QIAampDNA microkit (Qiagen). Total genomic DNA was extracted from tail, liver, and tibialis anterior muscle tissues by incubation for $4 \mathrm{~h}$ at $56{ }^{\circ} \mathrm{C}$ in DNA-extraction buffer $(50 \mathrm{mM}$ Tris- $\mathrm{HCl}, \mathrm{pH} 8,100 \mathrm{mM}$ EDTA, 0.5\% SDS) followed by phenol-chloroform-isoamyl alcohol extractions and ethanol precipitation.

\section{Bisulfite treatment}

Using the EZ Methylation Gold kit (Zymo Research, Orange, CA, USA) the extracted DNA was treated with sodium bisulfite in order to convert unmethylated cytosine residues to uracil. The converted DNA was eluted in $10 \mu \mathrm{l}$ of TE buffer $(10 \mathrm{mM}$ Tris- $\mathrm{HCl}, 0.1 \mathrm{mM}$ EDTA, $\mathrm{pH}$ 7.5). In all, $2 \mu \mathrm{l}$ of the post bisulfite-treated DNA were used for subsequent PCR amplification.

\section{PCR amplification of bisulfite-treated DNAs for subsequent pyrosequencing}

The PCR amplifications aimed at pyrosequencing were performed starting from 100 to $140 \mathrm{ng}$ of bisulfite-treated sperm, tail, liver, and skeletal muscle DNA. The PCR conditions were the same for all the genes tested, i.e. $94{ }^{\circ} \mathrm{C}$ for $15 \mathrm{~min}$, followed by 40 cycles of $94{ }^{\circ} \mathrm{C}$ for $30 \mathrm{~s}, 55^{\circ} \mathrm{C}$ for $30 \mathrm{~s}, 72{ }^{\circ} \mathrm{C}$ for $30 \mathrm{~s}$, and by a $72{ }^{\circ} \mathrm{C}$ for $10 \mathrm{~min}$ final extension step.

The GenBank reference numbers and corresponding sequence locations, the numbers of CpGs per amplicon, the sizes of the amplicons, and the sequences of the oligonucleotides used for PCR amplification are shown in Table 2. All reactions were performed with a PCR mixture (total volume $25 \mu \mathrm{l})$ containing oligonucleotides at $0.5 \mathrm{mM}$ concentration and $12.5 \mu \mathrm{l}$ HotStarTaq Master Mix (Qiagen).

The biotinylated PCR products were purified using streptavidin-sepharose beads (Amersham) and sequenced using the PSQ 96 Gold reagent kit (Biotage AB, Uppsala, Sweden) with the following primers: H19: 5'-GTGTAAAGATTAGGGTTGT-3', Meg3: 5'-GTTATGGATTGGTGTTAAG-3', Mest: 5'-TCAATATCAACTAAATAATC-3', Snrpn: 5'-GAATTGGAGTTGTGTGG-3', Peg3: 5'-AATTGATAAGGTTGTAGATT-3'.

The degree of methylation at each $\mathrm{CpG}$ site was determined using Pyro Q-CpG Software (Biotage AB). All samples were analyzed in duplicate.

In a previous study, the results obtained were double checked by comparing the technique used above, i.e. DNA bisulfite treatment and PCR amplification followed directly by pyrosequencing, with PCR amplification followed by amplicon subcloning and sequencing. The results were found to be similar.

\section{Statistical analysis}

Significances were evaluated using the unpaired Student's $t$-test and set at $P<0.05$.

\section{Declaration of interest}

The authors declare that there is no conflict of interest that could be perceived as prejudicing the impartiality of the research reported.

\section{Funding}

This work was supported by the FNS grant 3100A0-116021, by a grant from the Swiss Center for Applied Human Toxicology, and by the Swiss Academy of Medical Sciences.

\section{Acknowledgements}

We are indebted to Françoise Kuhne for sperm count procedure setting.

\section{References}

Alworth LC, Howdeshell KL, Ruhlen RL, Day JK, Lubahn DB, Huang TH, Besch-Williford CL \& vom Saal FS 2002 Uterine responsiveness to estradiol and DNA methylation are altered by fetal exposure to diethylstilbestrol and methoxychlor in CD-1 mice: effects of low versus high doses. Toxicology and Applied Pharmacology 183 10-22. (doi:10. 1006/taap.2002.9459)

Amstislavsky SY, Kizilova EA, Golubitsa AN, Vasilkova AA \& Eroschenko VP 2004 Preimplantation exposures of murine embryos to estradiol or methoxychlor change postnatal development. Reproductive Toxicology 18 103-108. (doi:10.1016/j.reprotox.2003.10.008)

Amstislavsky SY, Amstislavskaya TG, Amstislavsky VS, Tibeikina MA, Osipov KV \& Eroschenko VP 2006 Reproductive abnormalities in adult male mice following preimplantation exposures to estradiol or pesticide methoxychlor. Reproductive Toxicology 21 154-159. (doi:10.1016/j. reprotox.2005.07.009)

Anway MD, Cupp AS, Uzumcu M \& Skinner MK 2005 Epigenetic transgenerational actions of endocrine disruptors and male fertility. Science 308 1466-1469. (doi:10.1126/science.1108190)

Anway MD, Memon MA, Uzumcu M \& Skinner MK 2006 Transgenerational effect of the endocrine disruptor vinclozolin on male spermatogenesis. Journal of Andrology 27 868-879. (doi:10.2164/jandrol.106.000349)

Anway MD, Rekow SS \& Skinner MK 2008 Comparative anti-androgenic actions of vinclozolin and flutamide on transgenerational adult onset disease and spermatogenesis. Reproductive Toxicology 26 100-106. (doi:10.1016/j.reprotox.2008.07.008)

Armenti AE, Zama AM, Passantino L \& Uzumcu M 2008 Developmental methoxychlor exposure affects multiple reproductive parameters and ovarian folliculogenesis and gene expression in adult rats. Toxicology and Applied Pharmacology 233 286-296. (doi:10.1016/j.taap.2008.09. 010)

Arnaud P 2010 Genomic imprinting in germ cells: imprints are under control. Reproduction 140 412-423. (doi:10.1530/REP-10-0173) 
Buckley J, Willingham E, Agras K \& Baskin LS 2006 Embryonic exposure to the fungicide vinclozolin causes virilization of females and alteration of progesterone receptor expression in vivo: an experimental study in mice. Environmental Health 5 4. (doi:10.1186/1476-069X-5-4)

Carr MS, Yevtodiyenko A, Schmidt CL \& Schmidt JV 2007 Allele-specific histone modifications regulate expression of the Dlk1-Gtl2 imprinted domain. Genomics 89 280-290. (doi:10.1016/j.ygeno.2006.10.005)

Chapin RE, Harris MW, Davis BJ, Ward SM, Wilson RE, Mauney MA, Lockhart AC, Smialowicz RJ, Moser VC, Burka LT et al. 1997 The effects of perinatal/juvenile methoxychlor exposure on adult rat nervous, immune, and reproductive system function. Fundamental and Applied Toxicology 40 138-157. (doi:10.1006/faat.1997.2381)

Cummings AM 1997 Methoxychlor as a model for environmental estrogens. Critical Reviews in Toxicology 27 367-379. (doi:10.3109/10408449 709089899)

Elzeinova F, Novakova V, Buckiova D, Kubatova A \& Peknicova J 2008 Effect of low dose of vinclozolin on reproductive tract development and sperm parameters in CD1 outbred mice. Reproductive Toxicology 26 231-238. (doi:10.1016/j.reprotox.2008.09.007)

Eroschenko VP, Abuel-Atta AA \& Grober MS 1995 Neonatal exposures to technical methoxychlor alters ovaries in adult mice. Reproductive Toxicology 9 379-387. (doi:10.1016/0890-6238(95)00025-6)

Eroschenko VP, Swartz WJ \& Ford LC 1997 Decreased superovulation in adult mice following neonatal exposures to technical methoxychlor. Reproductive Toxicology 11 807-814. (doi:10.1016/S0890-6238(97) 00064-6)

Eroschenko VP, Amstislavsky SY, Schwabel H \& Ingermann RL 2002 Altered behaviors in male mice, male quail, and salamander larvae following early exposures to the estrogenic pesticide methoxychlor. Neurotoxicology and Teratology 24 29-36. (doi:10.1016/S0892-0362(01)00194-5)

Gaido KW, Maness SC, McDonnell DP, Dehal SS, Kupfer D \& Safe S 2000 Interaction of methoxychlor and related compounds with estrogen receptor alpha and beta, and androgen receptor: structure-activity studies. Molecular Pharmacology 58 852-858.

Jia D, Jurkowska RZ, Zhang X, Jeltsch A \& Cheng X 2007 Structure of Dnmt3a bound to Dnmt3L suggests a model for de novo DNA methylation. Nature 449 248-251. (doi:10.1038/nature06146)

Kaneda M, Okano M, Hata K, Sado T, Tsujimoto N, Li E \& Sasaki H 2004 Essential role for de novo DNA methyltransferase Dnmt3a in paternal and maternal imprinting. Nature 429 900-903. (doi:10.1038/nature 02633)

Kaneko-Ishino T, Kuroiwa Y, Miyoshi N, Kohda T, Suzuki R, Yokoyama M, Viville S, Barton SC, Ishino F \& Surani MA 1995 Peg1/Mest imprinted gene on chromosome 6 identified by cDNA subtraction hybridization. Nature Genetics 11 52-59. (doi:10.1038/ng0995-52)

Kuroiwa Y, Kaneko-Ishino T, Kagitani F, Kohda T, Li LL, Tada M, Suzuki R, Yokoyama M, Shiroishi T, Wakana S et al. 1996 Peg3 imprinted gene on proximal chromosome 7 encodes for a zinc finger protein. Nature Genetics 12 186-190. (doi:10.1038/ng0296-186)

Lee J, Inoue K, Ono R, Ogonuki N, Kohda T, Kaneko-Ishino T, Ogura A \& Ishino F 2002 Erasing genomic imprinting memory in mouse clone embryos produced from day 11.5 primordial germ cells. Development 129 1807-1817. (doi:10.1242/dev.00159)

Li E, Beard C \& Jaenisch R 1993 Role for DNA methylation in genomic imprinting. Nature 366 362-365. (doi:10.1038/366362a0)

Li JY, Lees-Murdock DJ, Xu GL \& Walsh CP 2004 Timing of establishment of paternal methylation imprints in the mouse. Genomics 84 952-960. (doi:10.1016/j.ygeno.2004.08.012)

Lucifero D, Mann MR, Bartolomei MS \& Trasler JM 2004 Gene-specific timing and epigenetic memory in oocyte imprinting. Human Molecular Genetics 13 839-849. (doi:10.1093/hmg/ddh104)
Morgan HD, Santos F, Green K, Dean W \& Reik W 2005 Epigenetic reprogramming in mammals. Human Molecular Genetics 14 R47-R58. (doi:10.1093/hmg/ddi114)

Okazaki K, Okazaki S, Nishimura S, Nakamura H, Kitamura Y, Hatayama K, Nakamura A, Tsuda T, Katsumata T, Nishikawa A et al. 2001 A repeated 28-day oral dose toxicity study of methoxychlor in rats, based on the 'enhanced OECD test guideline $407^{\prime}$ for screening endocrine-disrupting chemicals. Archives of Toxicology 75 513-521. (doi:10.1007/s002040100273)

Pant N, Kumar R, Mathur N, Srivastava SP, Saxena DK \& Gujrati VR 2007 Chlorinated pesticide concentration in semen of fertile and infertile men and correlation with sperm quality. Environmental Toxicology and Pharmacology 23 135-139. (doi:10.1016/j.etap.2006.07.012)

Roeleveld N \& Bretveld R 2008 The impact of pesticides on male fertility. Current Opinion in Obstetrics \& Gynecology 20 229-233. (doi:10.1097/ GCO.0b013e3282fcc334)

Shemer R, Birger Y, Riggs AD \& Razin A 1997 Structure of the imprinted mouse Snrpn gene and establishment of its parental-specific methylation pattern. PNAS 94 10267-10272. (doi:10.1073/pnas.94.19.10267)

Shimamura M, Kodaira K, Kenichi H, Ishimoto Y, Tamura H \& Iguchi T 2002 Comparison of antiandrogenic activities of vinclozolin and $\mathrm{D}, \mathrm{L}$-camphorquinone in androgen receptor gene transcription assay in vitro and mouse in utero exposure assay in vivo. Toxicology 174 97-107. (doi:10.1016/S0300-483X(02)00044-6)

Smilinich NJ, Day CD, Fitzpatrick GV, Caldwell GM, Lossie AC, Cooper PR, Smallwood AC, Joyce JA, Schofield PN, Reik W et al. 1999 A maternally methylated CpG island in KvLQT1 is associated with an antisense paternal transcript and loss of imprinting in BeckwithWiedemann syndrome. PNAS 96 8064-8069. (doi:10.1073/pnas.96.14. 8064)

Staub C, Hardy VB, Chapin RE, Harris MW \& Johnson L 2002 The hidden effect of estrogenic/antiandrogenic methoxychlor on spermatogenesis. Toxicology and Applied Pharmacology 180 129-135. (doi:10.1006/taap. 2002.9369)

Stouder C \& Paoloni-Giacobino A 2010 Transgenerational effects of the endocrine disruptor vinclozolin on the methylation pattern of imprinted genes in the mouse sperm. Reproduction 139 373-379. (doi:10.1530/ REP-09-0340)

Stouder C, Deutsch S \& Paoloni-Giacobino A 2009 Superovulation in mice alters the methylation pattern of imprinted genes in the sperm of the offspring. Reproductive Toxicology 28 536-541. (doi:10.1016/j.reprotox.2009.06.009)

Swartz WJ \& Eroschenko VP 1998 Neonatal exposure to technical methoxychlor alters pregnancy outcome in female mice. Reproductive Toxicology 12 565-573. (doi:10.1016/S0890-6238(98)00041-0)

Trasler JM 2009 Epigenetics in spermatogenesis. Molecular and Cellular Endocrinology 306 33-36. (doi:10.1016/j.mce.2008.12.018)

Tremblay KD, Duran KL \& Bartolomei MS 1997 A 5' 2-kilobase-pair region of the imprinted mouse $\mathrm{H} 19$ gene exhibits exclusive paternal methylation throughout development. Molecular and Cellular Biology $174322-4329$.

Zama AM \& Uzumcu M 2009 Fetal and neonatal exposure to the endocrine disruptor methoxychlor causes epigenetic alterations in adult ovarian genes. Endocrinology 150 4681-4691. (doi:10.1210/en.2009-0499)

Received 20 September 2010

First decision 18 October 2010

Accepted 9 November 2010 